\title{
A epistemologia da prática profissional docente: observações acerca de alguns desafios atuais
}

\section{The epistemology of professional practice teaching: remarks about some current challenges}

\author{
Gustavo Silvano Batista ${ }^{1}$ \\ Roberta Alves Gouveia ${ }^{2}$ \\ Renata de Oliveira Souza Carmo $^{3}$
}

\begin{abstract}
RESUMO
A epistemologia da prática profissional docente busca investigar os pressupostos e posturas das ações educativas e a tomada de decisões com base nesse exame. $\mathrm{O}$ intuito deste texto é apresentar como certas posturas teóricas interferem na práxis educativa,estabelecendo uma estreita relação entre a teoria e a docência. Muitas vezes, reproduzimos a nossa experiência discente aos nos tornarmos docentes e nos esquecemos de apreendera história epistemológica da prática profissional. Compreender a trajetória da educação, a função dos professores, seus trabalhos e saberes pode contribuir para a integração entre a teoria e a prática, de modo que elas forneçam instrumentos que auxiliem efetivamente o ensino de qualidade. Como a educação está em movimento e, consequentemente, é processual, dinâmica, progressiva e pretende mudar os sujeitos, nossas práticas devem estar munidas da consciência de que é tarefa urgente da educação contribuir com a formação de membros ativos da sociedade.
\end{abstract}

PALAVRAS-CHAVE: Epistemologia. Saberes docentes. Profissionalização docente.

\footnotetext{
${ }^{1}$ Doutor em Filosofia pela Pontifícia Universidade Católica do Rio de Janeiro (PUC-Rio). Professor Adjunto II Departamento de Filosofia da Universidade Federal do Piauí (UFPI). Professor Permanente do Programa de Pós-graduação em Filosofia da UFPI,Brasil. E-mail: gustavosilvano@ufpi.edu.br

${ }^{2}$ Mestranda em Artes pela Universidade Federal de Uberlândia (UFU). Professora de Piano e Percepção Musical no Conservatório Estadual de Música Cora Pavan Capparelli,Brasil. E-mail: rogouveia3@hotmail.com

${ }^{3}$ Especialista em Língua e Literatura Inglesas pela Universidade de Ribeirão Preto. Professora da área de Letras nos cursos de licenciatura e de Direito da Universidade de Uberaba (Uniube), Brasil. E-mail: renatadeoliveria.carmo@gmail.com
} 


\begin{abstract}
The epistemology of teacher professional practice investigates the assumptions and attitudes of educational and decision-making from that examination. The purpose of this paper is to present how certain theoretical positions interfere with the educational praxis, establishing a close relationship between theory and teaching. Often, we reproduce our students experience to become teachers and we forget to know the epistemological history of professional practice. Understanding the history of education, teachers' role, their work and knowledge can contribute to the integration between theory and practice so that they provide tools that effectively assist teaching quality. Since education is moving, and therefore is procedural, dynamic, progressive and by claiming to do to change the subject, our practices must be fitted with the awareness that it is an urgent task of education contribute to the formation of active members of society.
\end{abstract}

KEYWORDS: Epistemology. Knowledge teachers. Teacher professionalization.

\title{
Introdução
}

A constituição da pedagogia e do currículo aconteceu de modo histórico e político. Desde o século XVII, com a Didática Magna de Comenius, com a descoberta da infância contada por Rousseau em Emílio e com a institucionalização da educação por meio da invenção da escola, estamos no fluxo de uma longa tradição que também nos constitui. Simultaneamente, essa mesma tradição indica diversos entendimentos acerca das formas de educar as novas gerações. Desse modo, nessa história das didáticas, vemos, em linhas gerais, tentativas de garantir o acesso ao conhecimento considerado instituído e, ao mesmo tempo, de governar atitudes, hábitos e sentimentos, isto é, de disciplinar os indivíduos para que eles vivam bem e adequadamente em sociedade. 
Contudo, relacionar-se com essa tradição cultural não significa submissão ou adequação acrítica. Visto que não podemos negar e destruir totalmente essa tradição - mesmo que nos oponhamos a ela ou quando a acusamos por seus efeitos negativos e criticamos os seus equívocos, bem comoquando dizemos que dela nada queremos nem esperamos - ainda é dela que nos ocupamos. De outro modo, todos os elementos de nossa constituição social, assim como as teorias e práticas educacionais, não existem por si mesmas, não estão fixadas, não são eternas nem universais, mas estão fundamentalmente inseridas na tradição, constituída historicamente.

Assim sendo, a prática profissional docente perpassa toda a tradição da educação que, por força de nossa reflexão, merece uma compreensão de sua história que contribua para entendermos os caminhos pelos quais optamos ao exercer o ofício de educar.

Nessa perspectiva, pretendemos neste texto estudar qual é o papel da teoria - que está fundamentalmente relacionada à tradição como fluxo contínuo de referências e sentidos que nos constituem - no contexto prático do trabalho do docente universitário, visando enfocar o significado da epistemologia na prática profissional do educador contemporâneo.

Para isso, propomos um itinerário que se inicia discutindo o papel da teoria, seu significado e finalidade sob uma perspectiva epistemológica. A seguir, para um melhor entendimento do contexto prático do trabalho docente, abordaremos a trajetória da prática educativa comum aos professores universitários e seu reflexo nos dias atuais.

\section{Conceituando a epistemologia}

Ao refletir sobre a epistemologia da prática profissional docente é preciso responder a alguns questionamentos como: o que é epistemologia? Qual o tipo de racionalidade que se faz presente nos dias atuais?

De início, podemos afirmar que a Epistemologia, como área da Filosofia, é o estudo crítico dos princípios, hipóteses e resultados das 
diversas ciências. "Trata-se, pois, de uma reflexão epistemológica cuja preocupação fundamental é a de situar os problemas tais como eles se colocam ou se omitem, se resolvem ou desaparecem na prática efetiva dos cientistas" (JAPIASSU, 1992, p.27). Epistemologia significa, etimologicamente, o discurso (logos) sobre a ciência (episteme). Trata-se de um olhar reflexivo e crítico sobre as ciências, ou seja, um saber elaborado, sistematizado que questiona o processo pelo qual uma ciência se constitui como tal. Essa área nos oferece uma análise crítica da realidade, contra e ao mesmo tempo para além do senso comum (doxa). Assim, esse ramo da Filosofia busca compreender as teorias que fundamentam o conhecimento humano e ainda questiona, critica e investiga questões acerca do que já está constituído cientificamente. Desse modo, se algo já foi comprovado cientificamente, a epistemologia coloca em discussão os pressupostos de tal método de comprovação, visando verificar a consistência ou não dos argumentos fundamentais utilizados.

Especificamente relacionado à ciência da educação, o questionamento epistemológico se refere ao que fica pressuposto nas práticas pedagógicas, ao que não é dito pelo professor em suas atividades, mas que está efetivamente atuante e patente a sua prática educativa. Desse modo, a epistemologia da prática profissional docente visa tornar latentes os conteúdos que orientam a incorporação, produção e utilização dos saberes ensinados e sua aplicação na prática docente. São esses os saberes profissionais já interiorizados nos conhecimentos, habilidades e atitudes, em que o "saber-fazer", o "saber-ser" e o "saber-trabalhar em grupo" conduzem o "saber-relacionar-se com os alunos" e o "saber-verificar" seus conhecimentos, competências, habilidades e atitudes.

Assim, a epistemologia da prática profissional indica um "conjunto de saberes utilizados realmente pelos profissionais em seu espaço de trabalho cotidiano para desempenhar todas as suas tarefas" (TARDIF, 2004, p.255). De acordo com tal concepção, a epistemologia da prática é um estudo do conjunto dos saberes utilizados pelos sujeitos educativos, pelos profissionais 
e pelos docentes em seus respectivos espaços-tempos de atuação, para dar conta de todos os desafios que se colocam nas respectivas realidades nas suas mais variadas ações e atividades.

Posto isso, nossa discussão, a partir de agora, buscará responder a dois questionamentos: qual é o papel da teoria no contexto prático do trabalho do docente universitário? Qual é o significado e a finalidade da epistemologia na prática profissional desse docente? Iniciemos a abordagem pelo primeiro problema.

Com a crescente conscientização da necessidade de incentivo estatal e programas permanentes de formação docente, a educação tem se colocado como uma área fundamental de reflexão e mobilização acerca dos problemas que afetam o magistério nos diferentes níveis educacionais. Essa ciência tem atualmente vislumbrado caminhos significativos para a qualificação e atuação profissional dos docentes; porém, apesar disso, a docência ainda continua sendo alvo de investigações mais frequentes, amplas e sistemáticas, que possibilitam a compreensão de questões ainda não devidamente tratadas quando se fala da formação e da atuação docente, por exemplo, do ponto de vista da relação entre teoria e prática.

Diversos estudos apresentam a docência universitária sob permanente influência de paradigmas tradicionais no que tange a abordagens, metodologias e atitudes. Uma das noções que tem se revelado bastante equivocada é a concepção de que o domínio teórico de saberes específicos e de saberes pedagógicos aplicados na sala de aula garante, ao professor, um ensino de qualidade. De outro modo, a posse de conhecimento sistematizado que se refere à sua área de atuação é, sem dúvida, um instrumento fundamental para que o professor conduza seu trabalho; mas esclarecer qual é o papel da teoria no desenvolvimento das práticas educativas permitirá ao docente se tornar um crítico sobre seu fazer em sala de aula e como ele se relaciona com os demais interesses de seus alunos (LEITE e outros,2009, p.40). 
A docência é uma profissão exigente e, por isso, requer múltiplas destrezas do professor. Seu objetivo primeiro é promover a aprendizagem em nível superior, de modo que os alunos se formem profissionais aptos a exercerem a carreira escolhida de modo competente e articulado com as questões do tempo vivido. Nessa perspectiva, é necessário que o docente domine a área de conhecimento que leciona e, ao mesmo tempo, a didática que o ajuda a encontrar caminhos para um processo de ensinoaprendizagem mais efetivo e adequado.

Talvez o professor seja o profissional mais exigido em sua formação, em um processo complexo de qualificação marcado pela necessidade de contínua atualização. Em grande medida, tal complexidade está na observância de que o ato de lecionar depende essencialmente de conhecimentos específicos da disciplina ensinada e de conhecimentos didático-pedagógicos. No entanto, o domínio desses conhecimentos é ainda insuficiente para que o professor possa desenvolver seu trabalho prático, em razão da imprevisibilidade dos espaços de ensino-aprendizagem, já que “[...] professorar não é uma atividade burocrática para a qual se adquire conhecimentos e habilidades técnico-mecânicas" (PIMENTA, 1997, p.6). Há algo mais que a transmissão e aplicação de um conhecimento específico.

Isso significa que, no seu contexto de atuação, o professor irá se deparar com situações para as quais o domínio se revelará pouco seguro de conceitos, fórmulas, teorias e regras para a conquista da atenção e do entusiasmo de seus alunos. Uma das queixas mais recorrentes dos discentes é quanto ao fato de que os conteúdos e abordagens, muitas vezes, mostramse distantes de suas realidades e de seus interesses. (Re)pensar a relação entre a teoria e a prática pode não só melhorar a qualidade da educação, como também pode contribuir com a construção de uma epistemologia atual da prática profissional docente.

Essa ausência de parâmetros norteadores das práticas educativas dos professores é notada nos diferentes níveis educacionais, mas pode ser ainda mais expressiva na docência universitária, dada a dificuldade com que o 
professorado é admitido no ensino superior. No âmbito da universidade, o ensino - atividade mais depreciada e desqualificada por muitos docentes não tem uma primazia básica, mas é suplantado pela pesquisa, atividade considerada mais prestigiosa e basicamente desvinculada dele. Assim, os docentes universitários ainda se identificam mais com a carreira na qual foram formados do que com a docência, que tomam como uma carreira paralela e menos importante (BEHRENS, 2008, p.59; VASCONCELOS, 2008, p.79). A falta de identificação com o magistério e a valorização da pesquisa em detrimento do ensino são fatores que, entre outros, impedem o desenvolvimento e a sistematização do conhecimento sobre a prática docente nesse nível de ensino.

Ao considerarmos a docência no ensino superior, tomamos como ponto de partida a prática, que deve ser analisada e criticada à luz de uma teoria. Esta auxilia na reflexão sobre a atividade educativa desenvolvida em uma dada realidade histórico-social, com base na aplicação de conhecimentos científicos e didáticos que possam elucidar qualidades e deficiências do trabalho docente; "Ou seja, são as formas de agir que vão determinar as formas de pensar dos homens, as teorias, os conteúdos. A base do conhecimento é a ação prática que os homens realizam pelas relações sociais, mediante instituições" (MARTINS, 2003, p.140). Ao investigar sobre seu próprio fazer, os professores podem desenvolver a autonomia para a tomada de decisões sobre suas ações docentes em um contexto específico, ao mesmo tempo em que desenvolvem e atualizam sua identidade profissional. Evidencia-se, portanto, a necessidade de que esse processo se torne parte das ações docentes regulares não só no âmbito universitário, mas em qualquer nível de ensino (PIMENTA, 1997, p.7; ROCHA, 2006, p.68).

Ampliando a discussão, Malusá (2013, p.55-56) acrescenta que a prática não é mera aplicação da teoria. O domínio de fundamentos teóricos consistentes oferece sustentação para a docência, mas o professor precisa ser capaz de analisar seu contexto prático de atuação, a fim de sistematizar aqueles conhecimentos mais adequados à sua realidade de trabalho. A 
universidade é uma instituição que influencia e é influenciada pelo meio social que a cerca e, partindo de um espaço e de um tempo específicos, o docente deve ser capaz de mobilizar seus saberes a fim de propor práticas educativas que sejam produtivas e significativas para seus alunos.

A competência para conduzir a passagem do que é teoria para o que é prática decorre de uma reflexão cotidiana do professor sobre o que é abordado pelo seu fazer docente e como isso é desenvolvido. Essa imagem mais real de seu trabalho possibilita, ao professorado, a tomada de consciência sobre as melhorias necessárias ao seu processo de ensinoaprendizagem. Essa mudança implica também o investimento nas dimensões afetiva, social e cognitiva dos mestres, pois a sala de aula contempla o encontro de pessoas únicas em suas histórias e trajetórias de vida no árduo compromisso de produzir novos conhecimentos. Quando essa produção é efetivada, pode-se dizer que discentes e docentes saem dela transformados pela vivência de relações originais no campo científico e no campo humano, o que evidencia o potencial renovador da educação (MALUSÁ, 2013, p.56).

Renovação é a palavra que deve estar associada às nossas práticas educativas, pois a proposição de uma atividade de ensino-aprendizagem na universidade deve possibilitar o vínculo entre o conhecimento científico legitimado e o conhecimento empírico trazido à sala de aula com base nas experiências de vida do aluno. De acordo com Lara (1998, p.226), o papel da docência universitária não é ensinar coisas novas aos aprendizes, mas leválos a ver o que já sabem de maneiras diferentes. O autor lembra que, ao aplicar a teoria a uma vivência pessoal, o estudante experimenta o sentido original dessa palavra, que segundo o dicionário Houaiss (2009), é a "ação de observar, examinar”. Aprender implica, portanto, a aceitação de novos pontos de vista para a adoção de novas posturas.

Por sua vez, espera-se que o professor tenha igual oportunidade de refletir- individual e coletivamente- sobre seu trabalho, a fim de contribuir para a reelaboração das teorias que fundamentam seu fazer pedagógico. A 
atualização do conhecimento que norteia suas ações de ensino-aprendizagem está conectada a níveis de realidades histórico-sociais que ultrapassam o espaço acadêmico e, por sua vez, sofrem influências de outras dimensões: a família, a mídia, o trabalho, a religião, a economia etc. É preciso que a universidade reconheça, além do conhecimento formal que produz, a pluralidade dos saberes socialmente dados - que, como tradição, constituemse referências culturais - , a fim de incorporá-los criticamente às suas atividades, tornando-as mais significativas, interessantes e criativas. Nessa perspectiva, a necessidade de aprendizagem dos alunos passa a importar para a organização do ensino (LARA, 1998, p.226; MARTINS, 2003, p.9).

O papel da teoria no contexto do trabalho docente universitário deve ser o de oferecer perspectivas práticas, isto é, caminhos possíveis para a prática educativa nesse nível de ensino e não simplesmente rotas definidas. Uma possível conciliação entre essas duas dimensões pode ser apreendida pelos professores com o apoio, por exemplo,de programas de formação docente continuada. Essa é uma oportunidade para que a experiência individual de cada profissional possa ser compartilhada com as dos demais colegas e, coletivamente, o grupo reflita sobre os desafios enfrentados e proponha soluções viáveis para eles. Ao problematizar sua prática, cada professor é ator e autor do processo de construção de um modelo epistemológico docente que poderá, ao longo do tempo, compor o referencial teórico de uma didática para a docência universitária (MARTINS, 2003, p.11).

Ao abordarmos o segundo questionamento, ampliamos nosso olhar sobre a prática profissional docente e podemos estabelecer uma discussão mais profunda e eficaz sobre o ensino. Em seu contexto de atuação, os professores universitários desenvolvem e mobilizam diversos saberes pedagógicos que, não raramente, ficam encerrados entre as quatro paredes das salas de aula e, por essa razão, precisam ser socializados, visando à avaliação de sua relevância na docência no ensino superior. A busca por uma reflexão mais crítica e inovadora das práticas educativas desenvolvidas na 
universidade poderá resultar em avanços nas pesquisas em educação e na profissionalização docente nesse nível educacional, uma vez que

a finalidade de uma epistemologia da prática profissional é revelar esses saberes, compreender como são integrados concretamente nas tarefas dos profissionais e como estes os incorporam, produzem, utilizam, aplicam e transformam em função dos limites e dos recursos inerentes às suas atividades de trabalho. Ela também visa compreender a natureza desses saberes, assim como o papel que desempenham tanto no processo de trabalho docente quanto em relação à identidade profissional dos professores. (TARDIF, 2004, p.256)

Ao questionar as condutas desenvolvidas nas práticas docentes universitárias, a epistemologia ajuda a revelar quem é o profissional responsável por elas. A individualidade do professor universitário acaba por se mostrar quando suas ações didático-pedagógicas são examinadas criticamente, pois elas atuam como um espelho que reflete as várias dimensões que o formam: pessoal, profissional, sociocultural. A sua formação acadêmica contribui não só para o desenvolvimento de seu trabalho, mas também para suas vivências e experiências adquiridas nas diferentes dimensões da vida humana. Esses saberes ficam, muitas vezes, guardados em sua memória e, conforme a necessidade, o professor os aciona no exercício do magistério para explicar, mostrar, pedir, corrigir, avaliar, repreender, elogiar etc.

A educação se materializa em um processo complexo, porque ela é influenciada pelo momento histórico-cultural no qual está inserida e essa influência age sobre cada cenário educacional de modo diferente. Justificase, assim, a necessidade de que o professor possua um conjunto de saberes que devem ser utilizados, adaptados, atualizados e, muitas vezes descartados,com base na avaliação criteriosa do profissional no decorrer de seu exercício docente em um contexto específico de atuação. É preciso, pois, que o professor se conscientize de que a docência deve estar conectada a 
cada situação espaço-temporal. Assim, por uma prática pautada na interlocução de diferentes saberes, é que a epistemologia se expressa. Ela tem por finalidade revelar esses saberes, compreendendo como são integrados concretamente nas tarefas dos profissionais e como eles a transformam em função de sua realidade.

As epistemologias estão implicadas com a busca no sentido de compreender as práticas pedagógicas, os espaços-tempos educacionais, e, principalmente, as questões teórico-práticas, que lhes dão sustentação. Para tanto, essas questões precisariam ser constantemente refletidas, estar sempre abertas, inconclusas, para que os docentes se mantivessem, assim como toda a comunidade escolar, articulados à perspectiva da racionalidade, ou seja, da reconstrução do conhecimento e da interlocução de saberes. Portanto, essa proposta associa-se à constância em: questionar criticamente, valer-se da atitude de abertura, procurar tematizar o mundo da vida dos implicados, [...], ressignificar e refletir sobre as práticas pedagógicas. (MEURER; CANCIAN, 2006, p.02)

Ampliando a visão dessas autoras, Tesser (1995, p.97) acrescentou que a epistemologia se caracteriza não só pela compreensão do fazer pedagógico contextualizado, mas também pela capacidade do professor de problematizar sua própria prática educativa, integrando seu conhecimento teórico às suas ações docentes. Nesse processo, o profissional do magistério deve ser desafiado a fazer questionamentos originais sobre sua própria prática por meio de problemas delimitados em relação ao seu contexto. Dessa maneira, o processo educacional poderia ser vivenciado como um evento aberto e, portanto, suscetível a mudanças, pois o docente se admite como condutor do ciclo de criação e recriação de sua práxis. O reconhecimento de que o processo de ensino-aprendizagem está condicionado às condições sócio-históricas é um passo importante para que os profissionais da educação possam buscar permanentemente o 
aprimoramento de sua realidade de trabalho, baseado na construção de um conhecimento racional que deve ser compartilhado com seus pares.

Sendo assim, é necessário também que o professor tenha consciência de que sua prática educativa precisa ser submetida a um contínuo processo de autoavaliação, mediado por uma equipe formadora, para que seus saberes pedagógicos sejam aprimorados. O exame crítico-reflexivo possibilita a problematização do trabalho que o docente realiza em sala de aula: a abordagem dos conteúdos, as técnicas utilizadas, os instrumentos de avaliação, os relacionamentos humanos construídos etc. Para tal, é necessário que o professor se perceba não como um mero replicador de procedimentos didáticos, mas como um sujeito capaz de se responsabilizar pelo pensar sobre o fazer docente, que contribuirá com o desenvolvimento de conhecimentos que podem tornar seu processo ensino-aprendizagem mais significativo e eficiente.

Outro motivo para a construção de uma epistemologia da prática profissional docente é revelar como os saberes do magistério são empregados nas ações pedagógicas e como eles são integrados à prática, pois

pensar a epistemologia subjacente à prática pedagógica nos remete ao processo de formação inicial dos docentes, pois estas práticas são reflexos de um processo marcado pela racionalidade técnico-instrumental, que se apresenta de forma fragmentada. Neste ínterim, a visão que se constrói é uma visão educacional, limitada, fechada, que impossibilita o diálogo entre as diferentes ciências, assim como a clareza de seus objetos de estudo e a natureza dos saberes. (MEURER; CANCIAN, 2006, p.04)

As diversas deficiências na formação inicial dos professores costumam ser apontadas como um dos principais obstáculos para o desenvolvimento de práticas educativas competentes. No caso do ensino superior, essa questão se torna ainda mais preocupante, pois uma parte expressiva dos docentes vêm de outras áreas de formação, que não o magistério. Ao assumirem a docência, muitas vezes a competência pedagógica própria de cada área é 
insuficiente, dificultando o desenvolvimento de habilidades docentes fundamentais para abordar os conteúdos específicos de uma maneira mais interdisciplinar e adequada às demandas profissionais de seus alunos. Por esse motivo, Silva (2009, p.24) ressaltou que o processo de construção de uma epistemologia da prática profissional docente deve contemplar o momento da problematização e o da aplicação dos saberes construídos, no que a autora denomina "chão da escola".

O professor universitário é um profissional da educação que vem sendo cada vez mais desafiado na sua forma de ensinar. As exigências de uma sociedade da informação, altamente especializada, obrigam-no a atualizar seu fazer educativo de modo decisivo, para que ele seja capaz de enfrentar um panorama sociocultural cada vez mais desafiador, no qual ele e seus alunos se encontram inseridos. Para isso, um dos passos fundamentais é superar certos modelos de docência ainda baseados em condutas tradicionalistas, buscando uma prática docente que se reconstrói de modo crítico e cotidiano. Nesse sentido, sua principal fonte de saberes é a sua prática docente, que o desafia a dar novas formas, linguagens, perspectivas e movimentos ao seu conhecimento didático-científico para que seu ensino "fale" a alunos diversos, pertencentes a um dado tempo-espaço.

\section{Tempos históricos}

O estudo epistemológico da prática docente deve ultrapassar as teorias do conhecimento convencional. Isso significa dizer que questões éticas e históricas também estão em jogo nos processos de formação universitária, assim como as práticas hoje existentes nas escolas.

Uma das possibilidades de produção de conhecimento, de criar e recriar as práticas profissionais docentes é a articulação entre ensino e pesquisa, na perspectiva de que tal elo permite ao profissional a construção de seu próprio processo docente, contribuindo para a extrapolação de um modelo de educação fundado na reprodução de conteúdos e conhecimento. 
A docência universitária é um campo da educação que tem sido alvo de investigações ereflexões que buscam renovar as práticas educativas desenvolvidas nesse nível de formação. Isso é necessário, pois, nos tempos atuais, a universidade é um espaço de marcada diversidade social, cultural, política e econômica. As transformações pelas quais passou a sociedade brasileira nas últimas décadas foram, de alguma maneira, percebidas por essa instituição.

Implantada de acordo com os moldes europeus, a universidade brasileira foi criada com o propósito de atender a um público restrito e selecionado (MASETTO, 2008, p.10). Com o desenvolvimento do país, a expansão do ensino superior permitiu o acesso de estudantes de origens sociais, étnicas e culturais diversas. O espaço universitário, antes marcado por certa homogeneidade discente, passou a refletir com mais fidelidade as representações da comunidade externa quando possibilitou o ingresso de um alunado plural e diversificado. O mais recente Censo da Educação Superior mostra o significativo crescimento do ensino universitário no período entre 1980 e 2013. Em pouco mais de três décadas, o número de matrículas em cursos de graduação aumentou cerca de cinco vezes, chegando a um total de 7,3 milhões de alunos em 2013 (BRASIL, 2014).

A questão é que essa multiplicidade de sujeitos que acessam a universidade impõe desafios à docência. O modelo tradicional de aula centrada na transmissão de conteúdos que devem ser precisamente reproduzidos pelos alunos é insuficiente para mantê-los atentos, participativos e motivados para o estudo. Tal fato tem levantado questionamentos quanto à importância e ao significado da atuação docente no tempo presente.

Refletir sobre esses dilemas passa pela análise da formação docente, dos saberes necessários ao magistério, da relação entre a teoria e a prática e pelo papel da epistemologia na prática profissional do professor universitário. 
Todos que educaram e educam vivem três grandes tempos históricos, em termos do saber e do fazer pedagógico e curricular. O primeiro momento pode ser denominado como o tempo da "Neutralidade Iluminada"; seguido pelo tempo da "Suspeita Absoluta" e, na sequência; o tempo do "Desafio da Diferença Pura”.

Os educadores da primeira fase eram simples mediadores, neutros transmissores, iluminados orientadores de almas e corpos, em virtude de os educadores ainda estarem muito ligados à religião. Segundo Corazza (2005, p.08), "esse foi o tempo de uma construção muito abundante, que durou do final do século XIX até a metade do século XX”. Esse período

foi o tempo de criar a necessidade de educação para todos, consolidar a pedagogia, tornar a escola gratuita e obrigatória, formular currículos adequados ao social. Tempo de relacionar escola e mundo do trabalho, criança e aluno, aluno e produto, professores e profissão, metodologias e resultados, democracia e currículo. De formular as ciências da educação, que levaram os professores a conhecer mais e melhor o sujeito a ser educado, o ensino, a aprendizagem, o planejamento, a avaliação. (CORAZZA, 2005, p.08)

$\mathrm{Na}$ segunda fase, as principais ideias e práticas educacionais assumiram duas orientações: as liberais, a serviço das melhorias do capitalismo; e as marxistas, que se opunham tanto às formulações da Neutralidade Iluminada quanto às da Suspeita Absoluta de origem capitalista liberal. A educação assume a função de transmitir novos saberes, comportamentos e modos de ser. Era o tempo de Paulo Freire e de sua potente produção mundial: a "educação libertadora". Era o tempo da revolução em educação, apontou Corazza (2005, p.09).

Atualmente, todas as concepções e práticas atestam a presença dos diferentes, que povoam casas e ruas, salas de aula e pátios de recreio, dias e noites. Segundo Corazza (2005, p.10), “a pedagogia e o currículo, os professores e sua formação, as didáticas e as metodologias, a escola e a 
educação são impelidas a tornarem-se em tudo muito mais culturais e bem menos escolares, em relação aos tempos anteriores”.

Com esses apontamentos históricos, percebe-se que o debate sobre a formação do profissional da educação tem ocupado um espaço significativo nas pesquisas, buscando compreender que essa formação deve estar diretamente atrelada às realidades sociais escolares. Se no passado a ênfase estava na transmissão do conhecimento, hoje, as realidades sociais encontradas em sala de aula são mais complexas e exigem do docente uma formação mais ampla para que sua aula tenha significado.

Nesse cenário, é muito claro, que a "formação do professor não se encerra na formação inicial da universidade. A formação continuada é uma ação indispensável para o desenvolvimento de uma educação com mais qualidade” (FIGUEIREDO, 2005, p.23). Essa perspectiva está diretamente relacionada ao tempo atual vivido pela educação e reflete a inquietação e o desejo de que o ensino-aprendizagem seja significativo para o educando em um primeiro momento e que essa formação inicial, ministrada pela universidade, possa ser contributiva na vida profissional do futuro docente.

É necessária uma concepção crítica quando se trata de educação, pois é por meio dela que seremos profissionais pertencentes ao mundo real, material, histórico, nacional, no qual nos encontramos. É por meio da concepção crítica que a educação desenvolve sua função e utilidade, buscando produzir a transformação do homem e de sua realidade. Uma vez que acreditarmos na mudança dos sujeitos e da escola, o modelo de educação proposto pela Neutralidade Iluminada, apresentada por Corazza (2005, p. 8), já não se aplica mais. Nos tempos atuais, os saberes são provisórios, o conceito de profissão não é estático e a identidade dos grupos ocupacionais profissionais se altera. Nesse modelo está presente um profissional diferenciado, criador, que rompe com os modelos ultrapassados e inventa soluções. Reconsiderar a formação dos profissionais da educação e fortalecêlos são tarefas essenciais nesse momento. 
Ao reconhecermos a trajetória da educação e de seus profissionais, devemos compreender sua real função e estarmos contextualizados com o momento atual, priorizando a conexão dos alunos com sua realidade, buscando criar novas possibilidades em que discentes e docentes estão em constante aprendizado e construção.

Para Martins (2012, p.264),

após a modernidade surgiram novas necessidades na sociedade e, consequentemente novas formas de saber, devido à irrupção das tecnologias da informação e da comunicação, que constitui o elemento diferenciador nessa referência à modernidade ilustrada. A própria epistemologia, após a modernidade, apóia-se nas conseqüênciassócioculturais das actuais tecnologias, numa certa tradição filosófica (Nietzsche) e numa sequência de actualizações.

O autor também concorda com a linha de pensamento tratada neste estudo, na qual "a educação é processual, dinâmica, progressiva e com a pretensão de fazer mudar os sujeitos, convertendo-os em membros activos da sociedade" (MARTINS, 2012, p.264).

A utilização dos saberes cotidianos, trazidos pelos alunos para a sala de aula, e dos saberes científicos produzidos nesse mesmo ambiente, explorando a integração da teoria com a prática, podem contribuir para a eficácia da prática pedagógica e, consequentemente, produzir aprendizagens mais marcantes que poderão ser observadas na própria sociedade.

Com o intuito de sintetizar as argumentações aqui apresentadas, podemos dizer que o modo de conceber as relações entre teoria e prática se modifica de acordo com as sociedades, e por decorrência das concepções sobre educação, passa por períodos de conflito e reconciliação. O processo educativo está em movimento e em construção constante. Nessa perspectiva, a teoria deve estar fundamentalmente referida à ação, isto é, ter sua faceta prática. Por conseguinte, se isso não ocorrer, ela se torna inócua, vazia e sem 
sentido para o mundo social. Nesse contexto, a prática não pode ser defendida como um agir empírico e sem fundamentos, mas sim impulsionada por uma teoria.

\section{Considerações finais}

Ser educador é ser capaz de questionar, abandonar, largar, adquirir, readquirir, retomar e revitalizar suas práticas educativas. Os saberes docentes devem ser permanentemente atualizados, para que atendam às necessidades educacionais e formativas de cada grupo de alunos que o professor se relacionar. Esse processo de atualização deve ter origem nas vivências da sala de aula, ou seja, do relacionamento estabelecido entre mestres e aprendizes, com base no seu processo de construção do conhecimento acadêmico. Essa convivência nem sempre é tranquila, pois, no processo de aproximação, pode haver algum estranhamento e até algum distanciamento entre esses sujeitos, já que a diversidade humana presente nos espaços universitários exige do professor sensibilidade e competência para articular sua ciência às necessidades e aos interesses dos estudantes.

É nessa perspectiva que os grupos de formação docente para o ensino superior devem ser constituídos, para que os professores tenham a possibilidade de compartilhar tanto seus enfrentamentos na lida cotidiana do magistério quanto as ações por eles empreendidas para superá-los. Com base em um processo crítico-reflexivo, as teorias existentes podem ser examinadas e discutidas de modo a aprimorar as ações docentes por meio de sua conformação ao perfil do educador, dos alunos, da didática, do currículo, dos recursos etc. A teoria não é prescritiva, mas orientadora, direcionadora, adaptável e renovável à prática docente.

Os professores devem compreender e assumir, como parte de seu trabalho docente, a discussão e a avaliação de sua atividade pedagógica à luz dos referenciais teóricos existentes, para que esse conjunto de formulações sobre seu próprio trabalho seja não só reavivado, mas também 
sistematizado, divulgado e debatido em sua comunidade acadêmica e nas demais. Ao investigar seu próprio trabalho, os professores podem se tornar autores da construção de uma epistemologia da prática educativa, conferindo a ela uma relevância profissional. Na docência universitária, o compromisso com a reflexão e com a renovação de sua pedagogia significa não só o desenvolvimento de práticas educativas alinhadas ao tempo atual, mas pode ser uma resposta à desvalorização com que o magistério é ainda exercido por expressiva parcela de seus professores.

Assim, a teoria deve estar sempre a serviço da melhoria das práticas educativas em um movimento de ação-reflexão-ação, ou seja, o professor universitário deve compreender que é fundamental problematizar seu fazer pedagógico a fim de torná-lo mais apropriado ao aluno com quem ele compartilha o processo ensino-aprendizagem. Nesse sentido, o docente é ator, porque conduz o ensino, e é autor, porque parte de sua vivência no magistério para teorizar suas ações e condutas com a intenção de construir uma epistemologia da prática profissional docente.

Os programas de formação continuada de professores são de suma importância na conciliação das identidades do docente ator-autor, pois a função daqueles vai para além da apresentação de metodologias e técnicas de ensino. Tais programas devem propiciar também a teorização coletiva das práticas pedagógicas desenvolvidas em um dado contexto universitário para que esse processo crítico-reflexivo resulte em uma construção de conhecimento que legitime uma didática própria para o ensino superior.

A integração teoria-prática pode permitir ao professor universitário repensar sua docência não como uma carreira paralela ou como algo voltado para um público restrito. A problematização da docência na graduação deve considerar a diversidade de alunos que ingressam no ensino superior e que exigirão de seus mestres práticas educativas que contemplem a relação da carreira escolhida com as questões histórico-sociais do tempo vivido.

Assim, acreditamos que é necessário que o professor universitário descubra a sala de aula como o seu lugar. Ou seja, é o lugar onde sua 
identidade profissional se constrói de modo perene e se revela como tal, onde o vínculo com seus alunos é gerado e cultivado e seus saberes profissionais são mobilizados, desafiados, criados, adaptados etc. É nesse sentido que a valorização da sala de aula indica muito mais que a fundação da vida acadêmica no ensino. Porém, tanto o ensino quanto a pesquisa e a extensão devem ter a sala de aula como um lugar para o qual convergem.

\section{Referências}

BEHRENS, M. A. A formação pedagógica e os desafios do mundo moderno. In: MASETTO, M. (Org.). Docência na universidade. 9.ed. Campinas: Papirus, 2008.

BRASIL. Censo da Educação Superior 2013. Brasília: Ministério da Educação, INEP, 2014.2 Disponível em: <http://download.inep.gov.br/educacao_superior/censo_superior/apresentacao/2014/ coletiva_censo_superior_2013.pdf>. Acesso em: 27 ago. 2015.

CORAZZA, S. M. Nos tempos da educação: cenas de uma vida de professora.Revista da ABEM, Porto Alegre, n. 12, p.07-10, mar. 2005.

FIGUEIREDO, S. L. F. de. Educação musical nos anos iniciais da escola: identidade e políticas educacionais. Revista da ABEM, Porto Alegre, n. 12, p.21-30, mar. 2005.

HOUAISS, A. Dicionário eletrônico Houaiss da língua portuguesa. Rio de Janeiro: Objetiva, 2009. 1 CD-ROM.

JAPIASSU, H. Introdução ao Pensamento Epistemológico.7.ed. Rio de Janeiro: F. Alves, 1992.

LARA, T. A. A escola que não tive... O professor que não fui: temas de filosofia da educação. 2. ed. São Paulo: Cortez, 1998.

LEITE, D.; BRAGA, A. M.; FERNANDES, C.; GENRO, M. E.; FERLA, A.A avaliação institucional e os desafios da formação do docente na universidade pósmoderna. In: MASETTO, M. (Org.). Docência na universidade. 9. ed. Campinas: Papirus, 2008.

MALUSÁ, S. Estágio supervisionado e formação docente: indissociáveis e interdependentes no percurso da profissionalização. In: PRÓ-REITORIA DE GRADUAÇÃO, DIRETORIA DE ENSINO. Caderno de graduação da UFU: estágio, n.2. Uberlândia: UFU, 2013. 
MARTINS, E. C. Perspectiva epistemológica da realidade: "independência coexistência" nas formas de conhecimento. Educação e Filosofia, Uberlândia, v. 26, n. 51, p. 263-288, jan./jun. 2012.

MARTINS, P. L. O. A relação teoria e prática na formação do professor universitário: princípios e metodologia. Revista Diálogo Educacional, Curitiba, v. 4, n.10, p.131-142, set./dez. $2003 . \quad$ Disponível em: <http://www2.pucpr.br/reol/pb/index.php/dialogo?dd1=791\&dd99=view\&dd98=pb>. Acesso em: 06 ago. 2015. ISSN 15183483.

MASETTO, M. Docência universitária. 9.ed. Campinas: Papirus, 2008.

MEURER, A. C.; CANCIAN, V. A. Epistemologias do educar e práticas pedagógicas: reflexões docentes. In: Congresso Internacional em Educação: educação e sociedade: perspectivas educacionais do século XXI, 2006, Santa Maria RS. Santa Maria - RS: UNIFRA, 2006. p. 01-08. Disponível em: <http://www.unifra.br/eventos/jornadaeducacao2006/2006/pdf/artigos/pedagogia/ Acesso em: 31 jul. 2015.

PIMENTA, S. G. Formação de professores: saberes da docência e identidade do professor. Nuances, Presidente Prudente, v.3, n.3, set.1997. Disponível em: $<$ http://revista.fct.unesp.br/index.php/Nuances/article/view/50/46>. Acesso em: 11 jul.2015.

ROCHA, G. A. E agora... cadê os dragões? Uma pedagoga, mestre e doutora em Educação, vai aprendendo a ensinar no exercício da profissão. In: LIMA, Emília Freitas (Org.). Sobrevivências no início da docência. Brasília: Líber Livro, 2006.

SILVA, M. da.Complexidade da formação de professores: saberes teóricos e saberes práticos [online]. São Paulo: Editora Unesp; São Paulo: Cultura Acadêmica, 2009.

TARDIF, M. Saberes docentes e formação profissional. 4.ed. Petrópolis: Vozes, 2004. TESSER, G. J. Principais linhas epistemológicas contemporâneas. Educar, Curitiba, n.10, p.91-98, 1995.

VASCONCELOS, M. L. M. C. Contribuindo para a formação de professores universitários: relatos de experiências. In: MASETTO, Marcos. Docência universitária. 9.ed. Campinas: Papirus, 2008. 